\title{
LA VIVIENDA Y EL HÁBITAT EN LAS REPRESENTACIONES SOCIALES DE LOS SIN TECHO
}

\author{
Claudia Denisse Navas Rodríguez
}

Maestría en Gestión Estratégica de la Comunicación

... hasta la cuenta perdí de en cuántas casas he vivido. Porque como mis padres son tan pobres que no teníamos un terreno donde vivir, entonces, andábamos de colonos, cuidando fincas, en San Luis Talpa... Nos trasladamos un montón de veces, como seis veces. Hasta que llegué a la edad de 16 años y luego me vine a San Salvador, a trabajar (A. Rosales, comunicación personal, 13 de junio de 2016).

Este artículo muestra las representaciones sociales (percepciones, concepciones e imágenes) sobre la vivienda y el hábitat presentes en los testimonios de pobladores de asentamientos precarios de El Salvador. ${ }^{1}$ El déficit habitacional equivalente al 58\% de hogares salvadoreños se manifiesta en a) la carencia de vivienda (déficit cuantitativo); y b) la precariedad en la vivienda (déficit cuantitativo). El 78\% del déficit habitacional global se sitúa en el quintil de menores ingresos per cápita a nivel urbano (VMVDU, 2015). El déficit habitacional suele contarse sólo en números, pero contar significa también narrar historias y así ser tenidos en cuenta (Martín Barbero, 2002). Los testimonios y análisis han seguido los enfoques conceptuales sobre la vivienda propuestos por Rugiero (2012).

\section{A) VIVIENDA COMO VALOR SOCIAL: SOBREVIVIR.}

Los asentamientos precarios se originan de éxodos desde "paraísos perdidos". Los pobladores migran por mejorar su situación económica y/o huyen de situaciones de desastres. El hábitat social asalta "la ciudad formal" fuera de normativas de urbanización. "Toman un lote" en terrenos privados o parcelados, en áreas verdes, y en tierras al margen de la ciudad. Los sucesos

\footnotetext{
${ }^{1}$ Los testimonios se recolectaron en 2016, en asentamientos precarios urbanos y rurales del país. La Fundación Salvadoreña de Desarrollo y Vivienda Mínima, FUNDASAL, apoyó el acercamiento a los asentamientos para la tesis preparada por Claudia Denisse Navas Rodríguez para optar al grado de Maestra en Comunicación, octubre de 2016.
} 
más relevantes para las familias sin techo vinculados a la vivienda se refieren a dos categorías: 1) la inseguridad de seguirla habitando o volver a "vivir a la intemperie", ya fuera propiciada por una lluvia torrencial, un sismo o la vida útil de los materiales poco estables; y 2) la acogida de las nuevas generaciones que vuelve "nido" a la vivienda y permite proteger a quienes afirman la continuidad personal en el mundo.

B) VIVIENDA, UN PROCESO CONSTRUCTIVO DINÁMICO.

La construcción de la vivienda social incluye las dificultades: 1) construir en el largo plazo, en forma paulatina; 2) en topografías difíciles, 3) con riesgos de deslave o inundación, 4) con pocos recursos y 5) en forma perecedera e intuitiva. Tales dificultades convierten la vivienda en "un tesoro", un objeto caro, querido y con vida propia a la que se llama con diminutivos como "mi casita". La edificación de la vivienda requiere todo el ingenio, recursos y habilidades de los que son capaces los sin techo. Un adobe, una puerta, un muro se tornan símbolos parlantes de la historia de construcción. Construir desde la precariedad es siempre "ir habitando", "ir ahorrando" e "ir construyendo", todo al mismo tiempo, ya que no se puede de otra manera. La vivienda se vuelve una "alcancía”, el destino prioritario de ahorros e ingresos.

\section{C) VIVIENDA, B I E N D E} INTERCAMBIO Y TRANSFERENCIA

La "tierra prometida" es aquel suelo propio que alivia el costo físico, psíquico, económico y relacional de localizarse una y otra vez. La negativa de alquiler para familias numerosas, la imposibilidad de acceder a un crédito hipotecario y los conflictos con familiares acogidos como "allegados" confirman a los sin techo la representación social de que sólo quien tiene una vivienda propia tiene ganado el respeto. Los habitantes de lotificaciones, incluso cuando ya se haya cancelado la totalidad del valor del lote, afrontan también dificultades para legalizar su tenencia. Por otro lado, la vivienda pierde su valor patrimonial con retos que hacen inviable la vida en los asentamientos precarios: la afectación territorial por la violencia de pandillas y los riesgos derivados de la depredación y contaminación ambiental.

\section{D) VIVIENDA Y SATISFACCIÓN DE} NECESIDADES HUMANAS BÁSICAS. La vivienda se conecta con su entorno en el abastecimiento de servicios múltiples. A veces, la vivienda social alberga algún tipo de producción y/o comercio que suma a la subsistencia familiar: graneros, corrales, tiendas de conveniencia y más. El saneamiento básico y el abasto de agua se hacen por fosas de hoyo y cantareras que son puestas de forma artesanal. Las instituciones excluyen a estas poblaciones por no arriesgar a su personal en "zonas rojas". La topografía accidentada de los territorios dificulta la introducción de redes de agua y alcantarillado. Por su ubicación marginal a la ciudad y alta densidad de población, los asentamientos precarios hacen sacrificios cotidianos para acercarse a los servicios de educación, salud y transporte.

\section{E) VIVIENDA COMO SISTEMA REFERENCIAL Y CULTURAL.}

Los pobladores ven su comunidad desde su ideal: "un lugar de esfuerzos continuos, buena convivencia, 
apoyos recíprocos y unión entre gente pobre", esta visión es propiciada por la familiaridad con el vecindario y su paisaje. La diversión tiene un alto sesgo de género y poca apertura a la diversidad cultural: el deporte (entiéndase fútbol) es para la población masculina de cualquier edad, niños y jóvenes. La organización y trabajo para la comensalidad en las festividades religiosas, las ligadas a la familia $\mathrm{y}$ fechas fundacionales son tareas de las mujeres adultas y mayores. La convivencia comunitaria se desarrolla en calles, pasajes peatonales, espacios deportivos y edificios públicos poco equipados y degradados, cuya difícil topografía con la falta de iluminación pública y la demarcación territorial de pandillas los convierten en lugares de riesgo situacional. La señal de cable satelital suple el acceso cultural, cuyos artefactos se observan a menudo sobre los techos de las viviendas.

\section{F) VIVIENDA COMO GENERADORA} DE VIDA, RELACIONES Y AFECTOS. Las condiciones de hacinamiento y la calidad de los materiales de edificación de las viviendas reducen las posibilidades de intimidad. Es casi nula la separación entre el espacio público y el privado, pero se guarda silencio ante patrones de crianza violentos y prácticas discriminatorias de personas ancianas y disidentes sexuales. La violencia hacia las mujeres es reconocida si es física. Se naturalizan patrones patriarcales internalizados. Los programas a favor de las formas de convivencia respetuosa y dialógica no acompañan las mejoras en la infraestructura.
G) EL SIGNIFICADO SOCIAL DE LA VIVIENDA. UN AGRAVIO HISTÓRICO.

La vivienda adecuada y digna no es vista como un derecho humano sino como una mercancía inalcanzable. La incidencia ciudadana es vista como quebrantamiento del orden. En el poblador hay en una conciencia endeble de su estatus ciudadano, una representación débil de sí mismo (personal y colectiva) ante el poder del gobernante. El apoyo estatal esperado se concreta en: a) acceso a subsidios y créditos acordes a sus ingresos; b) proyectos de vivienda social en terrenos sin cultivo o en edificaciones en abandono y c) subsidio a la infraestructura básica y obras de protección. La mano de obra comunitaria está siempre dispuesta a sumarse.

En conclusión, el hábitat es localidad y relación entre personas que comparten un entorno para vivir. Los pobladores de los asentamientos deben desistir de esfuerzos aislados, tomar conciencia de ser un sector poblacional excluido de la ciudad, construir fraternidades y alianzas, y asumir el poder colectivo para viabilizar su condición y sus esfuerzos.

Los medios de comunicación han contribuido a estigmatizar a los asentamientos precarios; sus plataformas mediáticas deben enfocarse en la lucha de sobrevivencia del contingente poblacional que habita estos espacios.

El Gobierno salvadoreño tiene que tomar en sus manos la erradicación paulatina del déficit habitacional: consolidar una institucionalidad fuerte e idónea, 
revisar diversos mecanismos de acceso a financiamiento y al suelo para la vivienda de interés social, retomar formas participativas y novedosas; no debe permanecer indiferente ante una problemática que socava el uso del suelo y el medioambiente, la calidad de vida de la población trabajadora y las posibilidades de desarrollo de las nuevas generaciones.
6. Vivienda como generadora de vida relaciones $\mathrm{y}$ afecto

Relación cultural hombre territorio: identidad grupal, arraigo, alojamiento, expresión humana en obras y conductas, ser con - los - otros.

Idiosincrasia, afectos y valores.

Relación hombre - espacio en un contexto específico.

1. Vivienda como valor social

Solidaridad con el obrero que llega del campo.

Superar el hacinamiento e insalubridad en equidad de oportunidades.

Derecho de quienes no tienen posibilidades

individuales a una vivienda decente.

\section{Soluciones:}

desde un trozo de tierra con

una letrina de pozo hasta

diferentes tipos de

soluciones habitacionales.

5. Vivienda como sistema referencial y cultural

Enlace familia - vecindario, perteneciente $e$ interrelación.

Vivienda - comunidad en un territorio, elementos relacionados entre si.

Producto dinámico y jerárquico, en un espacio y tiempo determinado.

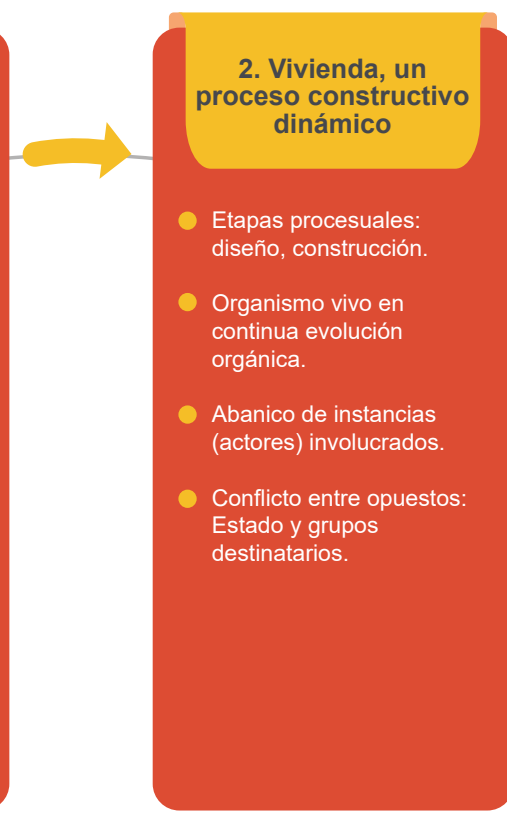

3. Vivienda, bien de intercambio y transferencia

Vivienda igual a casa edificio para habitar, estructura física que da abrigo y soporte material de la actividad humana.

Bien producible y transable.

Incluye connotación mobiliaria, de descendencia o linaje con un apellido $u$ origen común.

4. Vivienda y satisfacción de necesidades humanas básicas

Necesidades básicas: desarrollo personal (identidad, privacidad, intimidad) y social (sentido de pertenencia, interrelación).

Soluciones en términos de financiamiento.

Adaptabilidad dinámica del ser humano a varios ambientes. 


\section{REFERENCIAS BIBLIOGRÁFICAS.}

Barbero, J. M. (2002). La globalización en clave cultural: una mirada latinoamericana. Departamento de Estudios Socioculturales. Recuperado de www.infoamerica.org/documentos_pdf/martin_barbero3.pdf

Rugiero, A. (Mayo de 2012). Los aspectos teóricos de la vivienda en relación al habitar. Recuperado de http://www.revistainvi.uchile.cl/index.php/INVI/ article/view/263/782

Viceministerio de Vivienda y Desarrollo Urbano, Gobierno de El Salvador. (Octubre de 2015). Política Nacional de vivienda y Hábitat. Recuperado de http://www.vivienda.gob.sv/Archivos/pnvh/ Pol\%C3\%ADticaNacionaldeViviendayH\%C3\%A1bitatdeEISalvadorVice.pdf

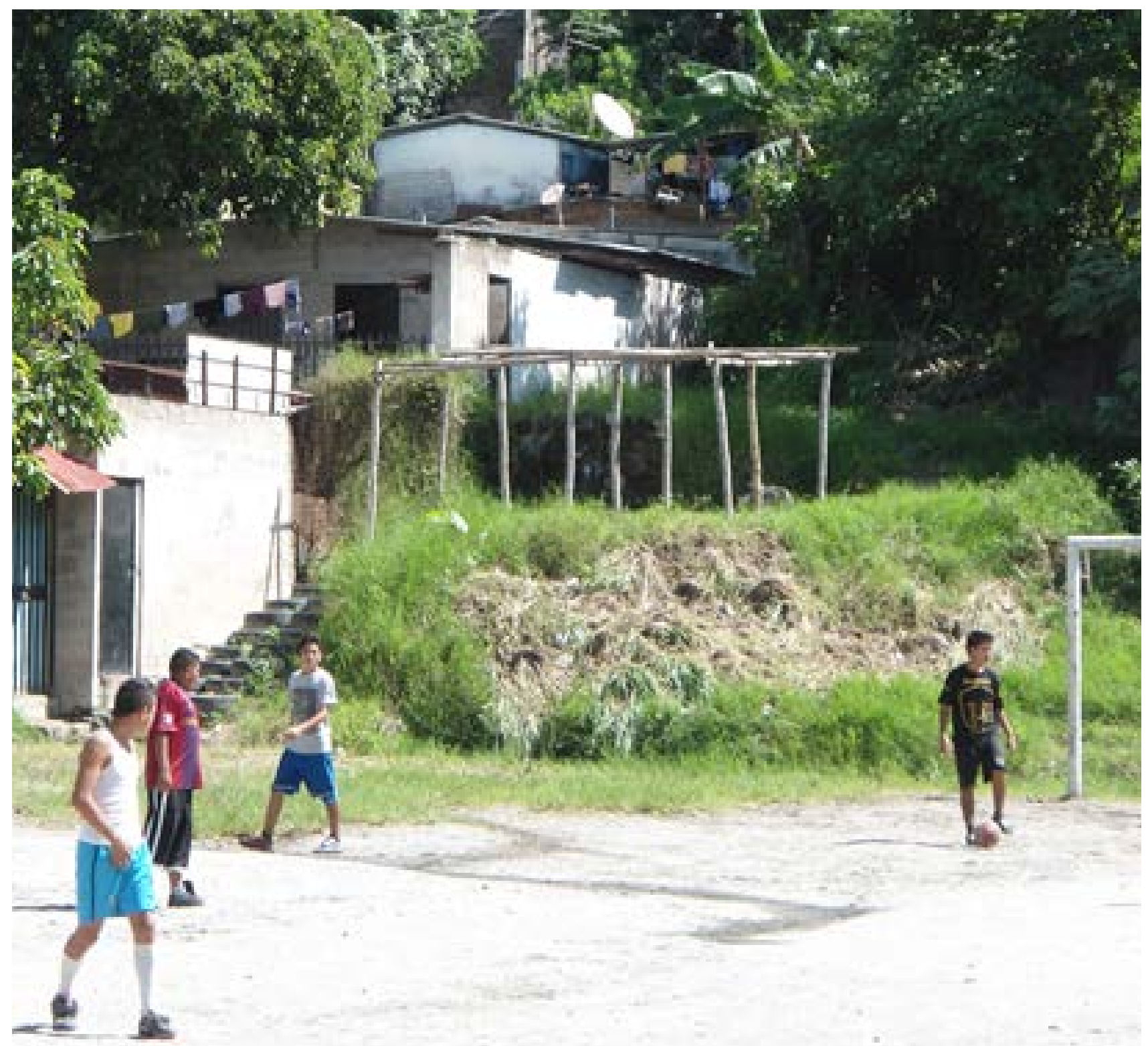

